\title{
Marketing in the New Millennium: Emerging Issues and Trends
}

\author{
Jaspal Singh \\ (Asst. Professor, Faculty of Business Studies, BGIET/Punjab Technical University, India)
}

\begin{abstract}
Given the focus on marketing research, the present paper combines both the academic and the practitioner perspectives to highlight several issues and emerging trends that will shape the role of marketing research in the new millennium. These include redefinition of marketing researcher, the ongoing nature of marketing research, qualitative research, Internet marketing research, and ethical issues in marketing research.
\end{abstract}

\section{The growing importance of marketing research}

As we have stepped into the new millennium, marketing research, or market research as it is also called, is becoming more and more important for companies facing intensifying competition. This trend is firmly in place and marketing research is expected to experience continued growth as long as competitively driven economies of the world expand.

Two principal reasons are cited for the continued growth of marketing research. First the speed of business has increased due to the diffusion of computers, digital technologies, and telecommunication devices. Such advances have enabled firms to be more responsive to be more responsive to customers through flexible manufacturing, and reduced cycle times in channel operations. Instant communication has become a prerequisite to developing a viable market. Although always important, marketing has assumed new significance in the organization, as the costs for misreading signals from the marketing place become increasingly steeper. As the detector and interpreter of signals and clues from the marketplace, marketing research has a critical role in providing "the voice of the customer" to management. Advances in technology have enhanced the scope, effectiveness, and efficiency of marketing research leading to its increased use.

The second reason for continued growth of marketing research is the implicit imperative for global operations as the end of Cold War has brought a new international system of globalization. As citizens of world are increasingly aware of consumption opportunities elsewhere, the demand for political, judicial, and delivery systems has increased in corresponding manner.

Although it has lingering presence in the world scene, nationalistic protectionism has lost much of its pallor. With more open markets, international competitors have moved into more markets of the world. At the same time, competition has become more global, flat or declining birth rates in developed countries of the world have rendered many product categories as saturated. As a result, the markets for products in developing and newly developed countries continue to expand as these countries have only recently experienced relative prosperity leading to an expanded middle class. Thus many of multinational companies (MNCs) based in developed countries are seeking to penetrate these developing markets. Marketing research can provide essential knowledge to management teams of firms entering new markets.

Despite the potential value of developing a market orientation and effectively utilizing marketing research, realizing these goals proves to be elusive for many firms struggling to become "learning organizations". While the perceived high cost of commissioning research appears to keep many firms from initiating marketing research, deploying marketing research is a complex process for the best of firms. The purpose of this article is to illuminate emerging issues and trends in marketing research as we enter a new millennium. In this way, we hope to boost the efforts of practitioners contributing to organizational learning. In this article we highlight several issues and emerging trends that will shake the role of marketing research in the new millennium. These include a redefinition of the marketing researcher, the ongoing nature of marketing research, qualitative research, quantitative research, international marketing research, internet marketing research, and ethical issues in marketing research.

Table 1

$>$ Emerging issues and trends in marketing research

$>$ Marketing researchers will participate more and more in marketing decision making

$>$ Managers will participate more and more in marketing research

$>$ More and more marketing research will be undertaken as an ongoing business operation

$>$ More marketing research problems will be addressed based on secondary data alone

$>$ The building of large databases that combine internal customer data with information available externally will gain momentum leading to increased use of database marketing 
$>$ More marketing decision will become automated

$>$ More interpretive research methodology (such as ethnography and grounded theory) will be implied

$>$ More integrated use of qualitative data with computer-driven analysis techniques will occur

$>$ Data analysis will make greater use of artificial intelligence pursuits such as artificial neural networks and genetic algorithms

> Marketing research has assumed a truly international character and this trend is likely to continue

$>$ Potential for global marketing programs will be assessed through multi-country marketing research

$>$ The use of secondary data in international marketing will continue to grow

$>$ The emergence of transnational segments will lead to greater standardization of international qualitative research

$>$ Multicounty telephone surveys will be conducted from a single location given the increased availability of ethnic interviewers locally

$>$ Attitude scales will become more widely used in cross-national research

$>$ Sampling methods used in cross national studies will increase in sophistication making greater use of probability techniques

$>$ Data analysis pursuits and techniques will become increasingly standardized in international marketing research

$>$ Project management for multi-country studies will become more of a distinctive skill area for research agencies

$>$ Use of bulletin boards, Web interviewing and chat rooms will be increased in exploratory research

$>$ The importance of Internet as a source of external secondary data will continue to grow especially in the realm of competitive intelligence

$>$ Organizations will increasingly use intranets to boost access to internal secondary data

$>$ More qualitative research will be conducted on the internet

$>$ The Internet will be increasingly used for observation

$>$ Internet surveys posted at a website will increase in popularity

$>$ Interactive downloadable surveys will become more feasible and attractive with advance in technology

$>$ The Internet will become a useful vehicle for conducting casual research

$>$ Sampling potential respondents who are surfing the Internet will become more meaningful

$>$ Marketing research reports will be routinely published or posted directly to corporate intranets

$>$ Due to partnering relationship, ethical conflicts between the client and the researcher will become less of a concern

$>$ Greater attention will be paid to the rights of respondents

$>$ Disguising versus disclosing the true purpose of the research will become more of an issue

$>$ Ethical issues related to observing and recording the behavior of respondents will gain importance.

$>$ The comfort level of the respondents during data collection will receive more attention

$>$ The use of over rely long questionnaires and sensitive questions will become a greater concern

$>$ Privacy will emerge as a primary concern for consumers

$>$ Preserving the anonymity of respondents will be a greater concern in business-to-business research

$>$ The marketing research industry will become aggressive in positioning itself as distinct from selling Codes of ethical conduct will receive more emphasis and significance

\section{A Redefinition of the Marketing Researcher}

Who is a marketing researcher? Who in the organization does marketing research? In the last century of the past millennium, the marketing researcher was a well-defined individual with certain qualifications and a set place in the organization. A commercial firm with an un-house marketing department had a clearly designated group of individuals who served in this staff function. Note that marketing research was a staff function and not a line function. Other than the interface in specific marketing research projects, marketing researchers had little interaction with marketing managers and did not participate in marketing decision making. Likewise, external providers of marketing of research had little interaction with marketing managers. However, as we have moved into the new millennium, this line of demarcation between marketing research and marketing, and thus the distinction between marketing research and marketing managers, is becoming thinner and thinner.

Marketing researchers will participate more and more in marketing decision making. The speed of business, the flood of information provided by the new technologies previously mentioned, and flatter organizational structures are driving this trend. In short, managers need help in processing more issues without the help of mid-level managers. The marketing researcher is accessible and is informed about these issues; therefore managers increasingly involve them in decision making. Managers want well-reasoned recommendations on the course of action to take, not just information about the issue or descriptions of possible courses of action. 
"Anyone who tells you they have a 5- or 10- year plan is probably crazy" said Hewlett-Packard Co. CEO Lewis E. Platt. "This is the age of scenario planning. You need not only speed, but agility "In light of recent concerns by marketing researchers about the limited impact of marketing research in the past, the blurring of the boundary between line managers and staff should be welcomed by the researchers as an opportunity to boost the action ability of research. However, this opportunity has an implicit cost in terms of more risk and more stress for researchers. In this riskier environment, marketing researcher directors must become more adept at winning in the competition for internal resources.

As the line and staff boundary blurs, marketing managers are becoming increasingly more involved in marketing research. In some organizations, for example, The United Parcel Service, marketing and other managers are rotated through the marketing research department. Conversely, it is also possible for marketing researchers to move out of the marketing research department and serve in marketing and related functions, such as planning. In yet other organizations, for example Coca-Cola, marketing research is now housed in brand management, and the global brand manager has the responsibility for marketing research for his/her brand. This leads to a natural integration of marketing research and brand management with several managers and or researchers working on several projects.

In real- time marketing situations, the "make and sell" paradigm has shifted to one characterized by "sense and respond". Dell Computer Corporation is one of the leaders in allowing consumers to design their own products from a menu of attributes, components, prices, and delivery options. Such an interactive online system has been called a "choice board". "Sense and respond" will also be evident in new product development. Online panels of "virtual customers" will help guide engineers' efforts during design process, instead of merely evaluating designs after prototypes have been produced. In this way, the boundary between engineers and marketing researchers will be blurred, also.

This trend toward making marketing research as amore of line function, rather than a staff function, is likely to continue and even accelerate in the near future where "sense and respond" will increasingly characterize firms' approach to business. Thus the traditional marketing researcher in a commercial firm narrowly focused on the production of presentations and reports for management will become a rare breed. The transition of marketing researchers to researchers cum decision makers has already begun. Indeed some of the most effective researchers of customer satisfaction are not only participating in decision making, but also are deployed as part of the team to implement organizational changes in response to customer satisfaction surveys. The availability of better decision tools and decision support systems is facilitating the transition of managers to researchers cum decision makers. Senior managers can now directly access internal and external secondary data from the microcomputers in their offices, analyze them, and make decisions. Thus, managers are acting more frequently as marketing researchers. As a consequence of these two simultaneous transitions, the line of demarcation between marketing researchers and marketing managers is becoming thinner and thinner. In the new millennium, good marketing researchers will be good marketing managers and vice versa. If either fails to do so, they will both be swept away by sudden unanticipated shifts in the marketplace, as consumers become increasingly empowered to choose new ways for their lives through rising incomes, technology, and information access. Thus Peterson coined the term "marketing research myopia" as a too narrow definition of who in the organization does marketing research.

\section{Marketing Research as an on-going operation}

Another paradigm shift is that more and more marketing research will be undertaken as part of normal on-going business operations, rather in response to specific marketing problems or opportunities. In the past much marketing research, particularly custom marketing research was undertaken in response to specific marketing problems or opportunities. For example, a firm faced marketing problems, such as loss of sales, or market share, price undercutting by a competitor, inadequate distribution, lack of product appeal, or ineffective advertising. On the other hand it may have faced an opportunity, such as potential for a new product introduction or expansion into a new market segment. A traditional approach to the research process was followed which began with a definition of the marketing research problem, formulation of a research design and the collection of primary data, data analysis, and report preparation and presentation.

Under the new paradigm, marketing research will be part of normal business activities. This will be true for secondary data obtained from syndicated sources as well as primary data collected by the firm. More and more marketing research problems will be addressed on secondary data alone. In the past millennium, collection of primary data was an integral part of the marketing research process. However, as we progress into the new millennium, this need not be the case. This will be made possible due to the extensive nature of secondary data available over the Internet, from business, government, and syndicated sources. This will include single source data. Single-source research follows a person's TV, reading, and shopping habits. After recruiting a test panel of households, the research firm meters each home's TV sets and surveys family members periodically on what they read. For background, most systems also track retail data, such as sales advertising, and promotion. Thus, single-source data provide integrated information on household variables, 
including media consumption and purchases, and marketing variables, such as product sales, price, advertising, promotion, and in-store marketing effort. The availability and use of such data will greatly increase. Another manifestation of this phenomenon is the building of large databases by combining customer transaction records with secondary information available from external sources in order to practice database marketing. Database marketing is also likely to grow as it enables efficient targeting at a microscopic, even individual level.

\section{Qualitative Research}

\section{Interpretive Methods}

More human-oriented research methodologies, such as ethnography, will be employed to understand nascent and emerging consumer issues. Many daunting issues facing researchers concern emotion, metaphor, nonverbal communication, and visual imagery. Not only do customers represent their experiences internally in these ways, but managers do, as well. It is no surprise than to observe a marked increase in marketing researchers' Utilization of alternative qualitative research techniques such as ethnography. Some advertising researchers report that the nuggets for advertising inspiration are more difficult to come by these days as consumers in focus groups increasingly tend to use lingo from advertising instead of reporting their more genuine responses. Ethnography involves observation techniques, and in depth interviewing in consumers' natural settings. Developed as a methodology in anthropology and sociology, ethnography projects can take several years to complete. "Blitzkrieg ethnography" where researchers invade consumer settings for an overnight, or two week observation excursion has been criticized for its disregard for the development of social scientists' most valuable research instrument- the social scientist's abilities for insight and for interpretation of meaning. Veteran ethnographers report such insights and understandings only begin to coalesce in their consciousness after spending a minimum of three months in field setting. IBM, Motorola etc. have all hired social scientists to help them figure out how consumers use products. Increased use of innovative qualitative techniques, such as ethnography, is expected in the coming years-not as a replacement for traditional qualitative techniques, but as a supplement.

In all qualitative methods, the researcher is the primary instrument for data collection and analysis. In interpretive methods to qualitative research and especially when an inductive approach is used, such as in grounded theory or critical realism research, this role for the researcher is amplified. The unrelenting demands for extended periods of iterative cycles of data collection, reflection, and analysis will keep likely keep newer approaches to qualitative research beyond the direct involvement of corporate researchers and managers. While consultants in these humanistic methods can be used, the benefit of having more insightful researchers participating in the ongoing dialogue among management decision makers will be lost unless firms develop more intimate relationships with researchers. These external researchers who are deliberately immersing themselves in the experience of the firm's customers over the extended periods of time will be highly regarded as consultants by innovative marketing groups. The alternative for organizations would be to structure field's assignments for researchers ranging from 06-24 months.

The insights derived from grounded theory approach suggest satisfaction is more evolutionary and socially oriented than previously thought. The studies' results suggest multiple satisfaction models operate in the satisfaction process and are mediated by product, person, and situational factors. A technologically oriented company such as Nokia, Intel or Sony would gain precious insights into what situational factors could be most influential for customer satisfaction by sponsoring such grounded theory research. The value of inductive approach used by Fornier and Mick is evident in surprising findings they presented about a topic regarded by many traditional researchers both in academia and in industry as mature. In this way, a fresh perspective was brought to a frequently researched topic of theory because the researchers were not driven by prior conception. We expect increased use of such approaches embodied by grounded theory as marketing managers seek new answers to old issues.

\section{Post-modern marketing research}

Interpretive research procedures such as those used in grounded theory research, critical theory, semiotics, hermeneutics, or phenomenology and historical analysis must be considered distinct from postmodern marketing research. While researchers espousing methodological pluralism would include interpretive research in the realm of science, the unbridled relativism inherent in much post-modern research challenges would challenge many such pluralists. While interpretive would take an epistemological position that knowledge is objective, the post-modern would take the position that knowledge is subjective, and that meaning is undecidable.

In the realm of applied research, a post-modern approach is presentation of how "cool-hunters" go to urban neighbourhoods to spot nascent fashion trends for youth. According to cool hunters observational research must be delicately pursued because the true innovators in such fashion want to stress tier individuality. For those who are "cool" doing what the others do is unpalatable, such as completing field survey forms. The 
circular and self-referencing logic seen in other post-modern works is illustrated by the following three rules of cool hunting:

1. Discovering cool makes it take flight;

2. Cool can only be observed;

3. By those who are cool.

Postmodernism is in many ways a rebellion against science and brings with it a denial of absolute truth. It is not surprising that the roots of postmodernism were first nurtured in the humanities- where art-not science is the focus. Literary analysis techniques have been used by post-modern researchers in close readings of variety of "texts" to discern assumptions and meanings not readily evident. While postmodernists may quickly suggest that research methods themselves can bias results, some postmodernists go on to declare that any misreading is inevitable and useful. If artistic interpretation is placed on an equal level with traditional research interpretation, such an assertion is more understandable. Postmodernists would readily make this placement of the relative value of science and art. In fact, "one can learn more from a reasonably good novel than from a solid piece of social science research"

While traditional researchers might perceive that industry has no time for art, this too needs to be rethought. On the whole, advertising creative comprise one group in the business world who share the postmodern mood, and its rejection of traditional survey methodology. While probably not sharing the post-modern mood, managers comprise another group who employ art or technique. In short, industry must have time for art because forms of art are being employed by key contributors throughout the realms of business on a daily basis. While we have already mentioned the fashion industry, the filmed entertainment industry seems well suited for post-modern research as artistic inspiration and understanding of cinema audiences have always been essential ingredients for producing commercially successful films. We further posit that postmodernist researches will likely lead researchers to re-examine the assumptions researchers bring to each step of the research process.

\section{Internet marketing research}

The World Wide Web (WWW) is the dominant component of the Internet and many use the term web and Internet synonymously. The internet is transforming the way marketing research is being conducted. Fueled by the Internet, the network era is exploding bringing about more sweeping change than the invent of personal computer. The technological infrastructure being created will enable rich, individualized telecommunication between marketers and individual consumers. As the network era ushers in ultimate customization or "one-to-one" marketing, marketing researches adapting to these technologies. Although online research is estimated to have accounted for 2 percent of all research spending in 1999, if current growth rates continue, half of all revenue for marketing research agencies would be derived from online research in 2004. Here we highlight several trends that are expected to accelerate as the new millennium progresses.

\section{Exploratory and qualitative research}

Bulletin boards (newsgroups) and web moderated interviewing consisting of Internet forums, and chat rooms will be increasingly used for exploratory research. They will be used to communicate with experts or individuals representing the target audience in order to obtain background information and develop an understanding of research context. Bulletin boards are conducted by inviting respondents to a specific Website where a discussion topic is posted. As responses are made to the question, others can read what has been submitted. Like a "slow-motion focus group", bulletin boards could be useful when a researcher needs to discuss issues with a panel of experts or participants in a beta test.

The importance of the Internet as a source of external secondary data will continue to grow. The Internet will be increasingly used for identifying marketing research information on companies. This includes information on firms that supply specific services, client organizations, as well as competitors, collaborators, and affiliates. Some data that would have been otherwise difficult to obtain, will become easily and quickly accessible through the Net. The Internet gives information on new and current subjects, which are not published yet. Information on the Web is of quality if it comes from original sources and it is current. The utility of the Internet for the market researcher is further enhances due to the easy accessibility and retrieval of information and easy cross-validation of the information available from several sources.

The current benefits of online secondary research to competitive intelligence efforts of companies have been overshadowed by the potential benefits of online primary research to customer research efforts. The excitement of receiving more rapid feedback from customers has been fanned by research agencies bringing automation to the previously slow and laborious data collection efforts they have offered. The gains of integrating information technologies with survey research practices have been trumpeted many times in recent years. Meanwhile, the undeniable benefits gained from using the World Wide Web to keep abreast of competitor's actions by collecting and analysing secondary data have arrived with much less fanfare. The 
competitive intelligence capabilities offered by the World Wide Web will become more pronounced in the international arena as penetration for the Internet increases in countries of the world.

An often-heard claim is that 90 percent of the information an organization needs is in the public domain. If this was true, much time and expense needed to be invested to actually come into possession of such information ten year ago. Five years ago, exhausting searches of the World Wide Web may not have returned much of that mythical "90 percent". Now, more complete information is available on the Web and the researcher now has the power of search agents (also called "bots" or "spiders") which can theoretically compare prices and features across every available retailer on the Internet. The "90 percent" is now more accessible than ever to the Web Savvy researcher and the availability and accessibility of this information will increase even further.

An example of the new sophistication in search agents is the third-party price comparison site called MySimon.com. Visitors to this site indicate the item of interest, and the search agent scans product and pricing information from a list of hundreds of online sellers stocking the item. Full--colour visual images of products can be included in what is returned by the search agent. A recent competitive intelligence project done by an international marketer of fashion watches returned rich information about 12 competitors' image and price positioning in cyberspace. This project not only suggested strategic image positioning for the fashion watch marketer, but also tactical moves in pricing, as well.

The freewheeling atmosphere prevalent in cyberspace currently encourages use of such search agents as these sites are seeking notoriety. However, such search agents were not developed specifically for researchers. (The sites featuring these agents typically earn a commission every time a buyer accesses a merchant site and ultimately buys an item through the search.) In time, researchers will likely develop their own search agents in order to avoid ethical dilemmas as the Web matures. The desire for more customized versions of these search agents will also spur researchers to develop their own search tools.

For those researchers with access to fee-based databases of periodicals, journals, and company-based information, such as $\mathrm{ABI} / \mathrm{Inform}$, Dow Jones Interactive, and Lexis/Nexis, background research can be accomplished with new power. For those without access to such fee-based databases, free-access sites remain extremely useful.

The implications of the recent advances in Internet research to managers are plain. Either develops a team that has become well versed in using the tools and resources of the Internet, or make decisions with lower quality information than competitors. Firms failing to do this will have their business models changed from providing valued goods and services to ones providing commodities-if they survive, at all. The good news for small businesses in all this is that the Internet brings them closer to having the rich information formerly available only to major corporations with multi-million dollar research budgets. Small firms who capitalize on this opportunity will be led by managers adept as Internet researchers.

Organizations will increasingly use intranets that greatly facilitate the search for access to internal secondary data. The Coca-Cola Company, for example, has developed powerful intranets applications that enable Coca-Cola managers worldwide to search for past and current research studies and a wide variety of marketing related information on the basis of key words. Once located, the information can be accessed online.

More and more qualitative research will be conducted on the Internet. Online focus groups will become commonplace. Even the preferred method compared to traditional focus groups for a wide range of scenarios. The Internet enables the researcher to reach segments that are usually hard to access: doctors, lawyers, professional people, working mothers and others who lead busy lives and are not interested in taking part in traditional focus groups. They offer several advantages including less time and low costs and can bridge the time and distance gap in recruiting respondents. Even individual depth interviews (IDIs) and projective techniques will gain popularity on the Net. The traditional disadvantages of the Internet in responses being less spontaneous, and limited group dynamics will be substantially overcome as the Internet becomes a way of life.

\section{Descriptive and quantitative research}

Internet surveys will increase in popularity. One reason is that the cost, in most cases is less than phone and mail surveys or personal interviews, three of the most common types of surveys. Also, the Internet survey is not as inconvenient as the phone call in the middle of dinner. The online survey can be completed in one's own time and place. Quick response time and the ability to target specific populations are also advantages worth noting. As Internet usage becomes more widespread, the disadvantages of this method in terms of sampling limitations and representativeness will be substantially reduces.

Surveys on the Internet can be conducted by way of e-mail, Web sites, or downloading from Web sites. The survey can be included in the e-mail or attached. Web surveys consisting of a long, single page written in HTML are currently accounting for 80 percent of data collection online. Click buttons and boxes, and fill-in text boxes are features used in these surveys.

Additional programming using CGI (a scripting-language that reads the data into a database when it is received) or HTML can automate the data entry process for such a Web survey. A multiple-page Web survey 
using fixed-form interactive authoring tools will present questions individually as in a computer-assisted telephone interview (CATI). A more graphically elaborate version of the multiple-page Web survey can be created using customized interactive programming. Downloadable surveys that shift the computing tasks to the respondent's PC have also been used successfully. Once the respondent downloads software provided by the researcher, a smaller file containing the survey is run on the respondent's computer. The resulting data file from this survey can then be uploaded the nest time the internet is accessed. The additional costs of programming and time required by respondents for downloaded able surveys (20 minutes to two hours) make downloadable surveys more demanding to field. However, with advances in technology this situation is likely to change making downloadable surveys more attractive.

The Internet will be increasingly used for observation. The Primary observations are being made by the number of times the Web page is visited and the time spent on the page. Further, various other links can be provided by the researcher on the Web page and it can be observed as to which links are accessed more often. This will provide the researcher with important information about the information needs of the individuals and also of the interests of the target segment. The analysis of the links from where the company site is being approached by the individuals will provide the market researcher with the important information regarding the consumers related interests and an in-depth analysis of the link sites will provide information on advertising, image, competitors, consumers, target market demographics and psychographics.

The Internet will become a useful vehicle for conducting causal research. Different experimental treatments can be displayed at different Web sites. Respondents can then be recruited to visit these sites and respond to a questionnaire that obtains information on the dependent variable. Thus, the Internet will provide a mechanism for controlled experimentation, although in a laboratory type of environment.

Sampling potential respondents who are surfing the Internet will become more meaningful as such samples will increasingly approximate populations of interest as the penetration of the Internet increases. More and more industries will meet this criterion. In software, computers, networking, technical publishing, semiconductors, and graduate education, it is rapidly becoming feasible to use the Internet for sampling respondents for quantitative research, such as surveys. Sampling on the Internet will also become practical for many non-computer-oriented consumer products. Extensive pre recruited pools of respondents will be more frequently used to approximate probability sampling. Such panels will be recruited via mail and personal contact not via the Internet. Panels such as these already exist and have millions of potential respondents from just about every country in the world. Such techniques will further enhance the generalizability of Internet research findings.

\section{Reporting}

Marketing research reports will be routinely published or posted directly to the Web on locations that are protected by passwords or on corporate intranets. These reports will incorporate all kinds of multimedia presentations including, graphs, pictures, animation, audio, and full motion video. It will be easy to integrate these reports and findings to become a part of the decision support system.

The benefits of intranets are not only increased organizational learning, but also enhanced productivity for the corporate marketing researcher. Once reports are posted to an internet, the corporate marketing researcher no longer has to directly field queries from managers throughout the organization who become interested in the result of specific studies. Time on the phone briefing such managers declines precipitously. In this way, the marketing researcher is freed to be more forward-focused, instead of repeatedly disseminating the same information to different managers.

\section{Ethics in Marketing Research}

Marketing research has often been described as having four stakeholders:

1 the marketing researcher;

2 the client;

3 the respondent; and

4 the public.

These stakeholders have certain responsibilities to each other and to the research project. Ethics issues arise when the interests of these stakeholders are in conflict and when one or more of the stakeholders are lacking in their responsibilities. Ethical issues are best resolved by the stakeholders behaving honourably. Codes of conduct are available to guide behaviour and help resolve ethical dilemmas. We discuss some of the common ethical dilemmas encountered at the various stages of the marketing research process.

The researchers must ensure that the research design utilized will provide the information needed to address the marketing research problem that has been identified. The client should have the integrity not to misrepresent the project and should describe the constraints under which the researcher must operate and not make unreasonable demands. Longitudinal research takes time. Descriptive research might require interviewing customer contact has to be restricted; the client should make these constraints known at the start 
of the project. Finally, the client should not take undue advantage of the research firm to solicit unfair concessions for the current project by making false promises of future research contracts. Partnering relationships between clients and researchers will become the norm in the future, helping to resolve such ethical issues.

Given the limitations of secondary data, it is often necessary to collect primary data in order to obtain the information needed to address the management decision problem. The use of secondary data alone when the research problem requires primary data collection could raise ethical concerns. Such concerns are heightened when the client is being billed a fixed fee for the project and the proposal submitted to get the project did not adequately specify the data collection methodology. On the other hand, in some cases it may be possible to obtain the information needed from secondary sources alone, making it unnecessary collection of expensive primary data, when the research problem can be addressed based on secondary data alone, may be unethical. These ethical issues become more salient if the research firm's billings go up, but at the expense of the client. Given the extensive nature of secondary data that will be abundantly available, these issues will become more salient in the future.

\section{Qualitative research}

When conducting qualitative research, ethical issues related to the respondents and the general public will be primary concern. These issues include: disguising the purpose of research and the use of deceptive procedures, videotaping and recording the proceedings, comfort level of the respondents, and misusing the findings of qualitative research.

All indirect procedures require disguising the purpose of research, at least to some extent. Often, a cover story is used to camouflage the true purpose. This cannot only violate the respondents' right to know but also in psychological harm. To minimize such negative effects, the respondents should be informed up-front that the true purpose of the research is being disguised so as not to bias the responses. After completing the research tasks, debriefing sessions should be held in which the respondents are informed about the true purpose and given opportunities to make comments and ask questions. We expect that greater attention will be paid in the future to avoid deceptive procedures that violate respondents' right to privacy and informed consent, for example, allowing clients to observe focus groups or in-depth interviews by introducing them as colleagues helping with the project.

An ethical dilemma involves videotaping or recording the focus group or the depth interview. Video or audio-taping the respondents without their prior knowledge or consent raises ethical concerns. Ethical guidelines suggest that respondents should be informed and their consent obtained prior to the start of proceedings, preferably at the time of recruitment. Furthermore, at the end of meeting, participants should be asked to sign a written statement conveying their permission to use the recording. This statement should disclose the true purpose of the research, and all people who will have access to the recording. Participants should be given an opportunity to refuse signing. The tapes should be edited to completely omit the identity and comments of the respondents who have refused. We expect that in future codes of ethical conduct will stipulate such practices.

Another concern that will receive more attentions is the comfort level of the respondents. During qualitative research, particularly in in-depth interviews, respondents should not be pushed beyond a point so as to make them uncomfortable. Respect for the respondents' welfare should warrant restraint on the part of the moderator or interviewer should not aggressively probe further.

\section{Quantitative research}

The marketing research industry will become more proactive and aggressive in positioning its undertaking as distinct from selling. Branding techniques will be incorporated more frequently, such as announcing to respondents that the research project is "CASRO-approved" or "meets the standards of ESOMAR". The use of survey research as a guide for selling or fundraising is clearly unethical. Another ethical issue that is salient in survey and observation research is respondents' anonymity. Researchers have an obligation to not disclose respondents' names to outside parties including the client. This is all the more critical if the respondents were promised anonymity in order to obtain their participation. The client is not entitled to the names of respondents. Only when respondents are notified in advance and their consent is obtained prior to administering the survey, can their names be disclosed to the client. . Even in such situations, the researcher should have the assurance that the client will not use respondents' names in the sales effort or misuse them in other ways. Researchers should not place respondents in stressful situations. Disclaimers such as "there are no right or wrong answers, we are only interested in your opinion" can relieve much of much of stress inherent in a survey. Ethical issues related to observing and recording the behaviour of respondents will gain in importance. Often the behaviour of people is observed without their knowledge because informing them may alter their behaviour. However, this can violate the respondents' privacy. One guideline is that people should not be observed in research in situations where they would not like to be observed by the public. However, 
observing people in public places like shopping mall or a grocery store is only appropriate if certain procedures are followed. Notices should be posted in these areas stating that they are under observation for marketing research purposes. After the data have been collected, the researcher should obtain the necessary permission from the respondents. If any of the respondents refuse to grant permission, the observation records pertaining to them should be destroyed. These guidelines should also be applied when using cookies on the Internet. Cookies are small bits of information about a user's previous access to a single web-site. These cookies are created by the Web site's programs and stored in a user's browser.

The researcher has several ethical issues and responsibilities to both the client and the respondents in the sampling process that will become increasingly important in the future. Pertaining to client, the researcher must develop a sampling design that is appropriate for controlling the sampling and non-sampling errors. When appropriate, probability sampling should be used. When non probability sampling is used, effort should be made to obtain a representative sample. It is unethical and misleading to treat non-probability samples as probability samples and to project the results to a target population. Researchers must be sensitive to preserving the synonymity of respondents when conducting business-to-business research, employee research, and other projects in which population size is small, it is easier to discern the identities of the respondents than when the samples are drawn from a large population. Sampling details that are too revealing or verbatim quotations in reports to the client can compromise the anonymity of the respondents. In such situations, the researcher has the ethical obligation to protect the identities of the respondents, even if it means limiting the level of sampling detail that is reported to the client and other parties.

\section{Future direction in ethics}

As clients become more sophisticated, they will increasingly participate in marketing research decisions along with the researchers. This will occur as researchers participate more in marketing decision making, as discussed earlier in the paper. This blending of the roles will lead to more openness, communication, and understanding, minimizing the ethical conflicts.

Greater attention will be paid to preserving the rights of respondents. The invasion of respondents' privacy has already become a burning issue. For example, the use of telephone surveys is being threatened by the legislations of different countries. In the network era, the individual consumer's power position among the stakeholders will improve so that marketers will increasingly rely on consumers' permission to offer them goods and services online. Such concern will become a critical issue in the future of online business. Consumer advocates assume that consumers will ultimately own historical profile of activity with business. If the issue of privacy for individual consumers can not be satisfactorily resolved for consumers, government regulatory intervention could be likely.

One way in which this dilemma will be resolved is by the marketing research industry voluntarily adopting practices and codes of conduct that show a greater respect for the rights of the respondents and general public. While several marketing and marketing research associations have ethical guidelines, a truly international code of marketing research ethics is lacking. However, such a code should emerge in the near future.

\section{Conclusion}

As we step into the new millennium, the field of marketing research holds great promise. In this paper we have attempted to combine theoretical and practitioner perspectives to identify the issues and trends pertinent in the new millennium. We also want to conclude on the same note, the need to blend these two perspectives. For the promise and the potential of marketing research to be realized, it is crucial that the gap between academic and commercial marketing research be bridged. This can occur by academic researchers examining substantive issues that are managerially relevant. Simultaneously, applied marketing researchers must realize that marketing research should be grounded in theory. Theory enables us to meaningfully interpret and integrate the findings with previous research. Thus, a cross-fertilization of academic and applied research is needed.

\section{Dedication}

This Research Paper is lovingly dedicated to my respective parents and other family members who have been my constant source of inspiration. They have given me the drive and discipline to tackle any task with enthusiasm and determination. Without their love and support this project would not have been made possible.

\section{ACKNOWLEDGEMENT}

I would like to acknowledge the contributions of the following group and individuals to the development of this research paper. I am heartily thankful to Ms. Sheetal Singla, Professor, Faculty of Business Studies, BGIET, Sangrur, to Dr. Amrish Dhawan, Principal, RMC, Patiala, and to Dr. Janardhanan K.P., 
Director, BGIMT, Sangrur, whose encouragement, guidance and support from the initial to the final level enabled me to develop an understanding of the subject. To my truly great friend Shaukat Ali, who has made available his support in a number of ways. Lastly, I offer my regards and blessings to all of my students who supported me in any respect during the completion of the project.

\section{Refrences:}

[1]. Adams T., “A New Dimension for Market Researchers”, Marketing Research, August, 1997

[2]. Akaah, I.P. "Influence of Deontological and Technological factors on Research Ethics evaluations"- Journal of Business Research(1997, Vol.11)

[3]. Armstrong, R.W. "The Relationship between Culture and Perception of Ethical Problems in International Marketing"

[4]. Aslo, J.S. and Nafria, E., "The AUDE integral information analysis derived from consumer panels and audience panels"

[5]. Bacon,L., "Data Mining in Marketing"

[6]. Barabba, V.P. and Zaltman, G. , Hearing the Voice of Market

[7]. Bass, F.M., "The Future of Research in Marketing: Marketing Science"

[8]. Brown,S., "Marketing and literature: the anxiety of academic influence"

[9]. Choi, J., Cooper, K. and Hamner, P. (2008), "Identifying Target Customers"

[10]. Clemons, E.K. and Bardley, S.P., "Strategic uncertainity and the future of online consumer interaction"

[11]. Costa, J. (1998), “ Power tools for multicultural marketing researchers"

[12]. Decision Analyst. http//www.secisionanalyst.com/online/acop.htm

[13]. Dutka, A., Competitive Intelligence for the competitive edge, NTC Business Books, Lincolnwood

[14]. Fassino,M. "Neural Networks; using the past to forecast the future"

[15]. Godin, S., Permission Marketing, Simon and Schuster, New York, NY

[16]. Kotable, M. and Helson, K., Global Marketing Management, John Willey and Sons, New York, NY

[17]. Richards, L. Using NVivoin Qualitative Research, Sage Publication, Thousand oaks, CA

[18]. SCOLARI, http//www.scolari.com

[19]. Slater, S.F. and Narver, J.C. "Market oriented is not enough; build learning organization" , in Deshpande, R.(Ed.), Developing a Market Orientation, Sage Publication, Thousand oaks, CA

[20]. Vitell, S. and Ho, F.N. “ Ethical Decision Making in Marketing; a synthesis and evaluation of scales measuring the various components of decision making in ethical situations"

[21]. www.12Manage.com 